design of the social brain. We highlight the importance of the distinction between in-group and out-group membership that lies at the heart of intergroup conflict, violence and xenophobia. Our hypothesis (the out-group intolerance hypothesis) provides an explanation for the disparities in the prevalence of schizophrenia across the world and for the higher risk of this condition among immigrants and city dwellers. We propose that our hypothesis can account for a range of disparate epidemiological and other findings regarding schizophrenia that have thus far defied explanation by other theories, including the Darwinian by-product formulations reviewed by Kelleher et al.

1 Kelleher I, Jenner JA, Cannon M. Psychotic symptoms in the general population - an evolutionary perspective. Br J Psychiatry 2010; 197: 167-9.

2 Burns JKP. An evolutionary theory of schizophrenia: cortical connectivity, metarepresentation, and the social brain. Behav Brain Sci 2004; 27: 831-55.

3 Crow TJ. Is schizophrenia the price that Homo sapiens pays for language? Schizophr Res 1997; 28: 127-41.

4 Abed R, Abbas M. A reformulation of the social brain theory for schizophrenia: the case for outgroup intolerance. Perspect Biol Med 2011; in press.

Riadh Abed, Consultant Psychiatrist and Medical Director, Rotherham, Doncaster and South Humber NHS Mental Health Foundation Trust, St Catherine's Hospital, Doncaster DN4 8QN, UK, email: Abedrt@btinternet.com; Mohammed Abbas Consultant Psychiatrist, Bradgate Mental Health Unit, Leicester, UK

doi: 10.1192/bjp.198.4.325a

Kelleher et $a l^{1}$ note the significant prevalence of non-clinical psychotic symptoms in the general population and discuss some hypotheses regarding its evolutionary survival. One theory not mentioned by them or those who have so far responded is a trait known as schizotypy. While accepting that to some degree the whole topic is rich with speculation, I suggest that schizotypy may be the missing piece in the puzzle. What follows is necessarily a brief summary of some of the relevant literature.

Differing from both schizotypal and schizoid personality disorders, schizotypy ${ }^{2}$ is a heritable trait associated with an increased likelihood of creativity and of religious or mystical experiences. Importantly for this discussion, schizotypy also appears to be necessary but not sufficient for the development of schizophrenia, although not all those with schizotypy develop psychotic illnesses.

The four key dimensions of schizotypy are unusual experiences (which may be considered to be related to positive symptoms), cognitive disorganisation (related to thought disorder), introverted anhedonia (related to social withdrawal and depression) and impulsive non-conformity. This last is related to some of the disturbed behaviour, such as aggression and selfharm, seen in a range of psychiatric illnesses, including psychosis.

Regarding creativity, additional research by $\mathrm{Nettle}^{3}$ suggests that different dimensions of schizotypy are associated with different types of creativity. Nettle \& Clegg further find that schizotypy is associated with increased 'evolutionary fitness' due to a greater number of sexual partners (and therefore offspring) in those with the unusual experience and impulsive non-conformity dimensions of the trait. ${ }^{4}$ In those with the former but not the latter dimension, the relationship with mating success is mediated by creativity. Nettle \& Clegg have proposed that schizotypal traits, which in this case may be a proxy for some non-clinical psychotic symptoms, have therefore persisted because their potential negative effects are offset by enhanced mating success.

Regardless of the outcome of the search to understand the persistence of psychotic symptoms in human beings and of possible future research involving those who have the non-clinical psychosis phenotype, it is important for people working in mental health services to remember that not all those they encounter with symptoms are ill. For those that are unwell, there will be other aspects of their existence that are positive and that may be life-enhancing for them and those around them. They should be encouraged to develop these aspects of themselves as part of their long-term recovery, in addition to the treatment and support they receive from health services, carers and friends.

1 Kelleher I, Jenner JA, Cannon M. Psychotic symptoms in the general population - an evolutionary perspective. Br J Psychiatry 2010; 197: 167-9.

2 Claridge G (ed). Schizotypy: Implications for IIIness and Health. Oxford University Press, 1997.

3 Nettle D. Schizotypy and mental health amongst poets, visual artists, and mathematicians. J Res Pers 2006; 40: 876-90.

4 Nettle D, Clegg H. Creativity, schizotypy and mating success. Proc Roy Soc B: Biol Sci 2006; 273: 611-5.

Marcia Willis, Locum Consultant, Child and Adolescent Psychiatrist, Brent Child and Family Clinic, Warranty House, Dudden Hill Lane, Neasden, London NW10 1DD, UK. Email: marcia.willis@nhs.net

doi: 10.1192/bjp.198.4.326

\section{Don Quixote and Sancho Panza: folie à deux?}

Martins de Barros \& Busatto Filho date the first report in fiction of folie à deux to the Brazilian author Machado de Assis in 1879. ${ }^{1}$ I submit that the first fictional account of 'shared delusions' was by Miguel de Cervantes over 250 years before. Cervantes wrote Don Quixote de la Mancha in or around 1604, publishing the first part in 1605 and the second, a decade later.

In Don Quixote, the eponymous hero, we have a domineering and voluble fantasist driven 'out of his wits' by the undue influence of books of chivalry: 'He so buried himself in his books that he spent the nights reading from twilight till day break and the days from dawn till dark; and so from little sleep and much reading, his brain dried up and he lost his wits.' ${ }^{2}$ His character is steeped in rich descriptions of grandiloquent and persecutory delusions, polymorphic hallucinations and cognitive blunting. Sancho Panza, his squire, whom he enlists as his companion for his travels, is described as 'an honest man - if a poor man can be called honest - but without much salt in his brain-pan.'

So we have a dominant Don Quixote, who has lost his reason, and a submissive, not so bright Sancho Panza, thrown together through much of their travels, creating a situation ripe for the development of folie à deux. And indeed we see a slow erosion of reason in Sancho Panza. He initially displays some resistance and skepticism to Don Quixote's delusions about windmills being monstrous giants or St Benedict's monks being a crew of wicked and diabolical 'perfidious scoundrels'. But he increasingly becomes convinced of the veracity of Don Quixote's beliefs. One example should suffice, the example of the balsam of Fierabras. This is a concoction that Don Quixote claims he can make on the cheap. He tells Sancho Panza, 'If ever you see me cut through the middle in some battle [ ... ] you have only to take the part of my body that has fallen to the ground and place it neatly and cunningly, before the blood congeals, on to the half that is still in the saddle, taking special care to make them fit exactly. Then you must give me just two drops of this balsam to drink and, you will see, I shall be as sound as an apple.' ${ }^{2}$ Sancho replies, 'If that is so, from now on I renounce the governorship of the promised isle, and all I want in payment for all my good services is for your worship to give me the recipe for that marvelous liquor.'2 